\title{
A network-based HIV prevention intervention for Tajik migrant workers who inject drugs
}

Judith A. Levy ${ }^{1}$, Mary Ellen Mackesy-Amiti ${ }^{1 *}$, Makhbatsho Bakhromov², Jonbek Jonbekov² and Carl A. Latkin $^{3}$

1 University of Illinois at Chicago, School of Public Health, Chicago, Illinois, USA

2 PRISMA Research Center, Dushanbe, Tajikistan

3 John Hopkins Bloomberg School of Public Health, Baltimore, Maryland, USA

* Corresponding author: Mary E. Mackesy-Amiti, University of Illinois at Chicago, School of Public Health MC 932, 1603 W. Taylor St., Chicago, Illinois 60612. Tel. +1 312-355-4892. Email:

mmamiti@uic.edu.

This research was supported by a grant from the National Institute On Drug Abuse of the National Institutes of Health (USA) under Award Number R21DA039068. The content is solely the responsibility of the authors and does not necessarily represent the official views of the National Institutes of Health.

Preprint v.1, March 1, 2021 
HIV prevention for Tajik migrant workers

\section{Abstract}

We developed and pilot-tested the Migrants' Approached Self-Learning Intervention in HIVIAIDS for Tajiks (MASLIHAT). We recruited 30 Tajik labor migrants who inject drug in Moscow as peer educators (PEs) to attend the 5-session intervention, then share what they learned with their peers. Each PE recruited two drug-injecting network members for interviewing about their drug and sexual behavior at baseline, 6 weeks, 3 months, and 6 months post-intervention. GEE and mixed effects regression tested time and participant type effects on each outcome. HIV knowledge and risk perception increased among both PEs and network peers, while use of shared syringes, condomless sex, sex with a sex worker, and alcohol use decreased significantly for both groups at 6 weeks and 3 months with a sustained effect through 6 months. The MASLIHAT intervention proved successful in disseminating HIV prevention information and reducing HIV risk behavior over 6 months among both PEs and network members.

Key words: HIV prevention, injection drug use, peer networks, migrant workers, Tajik migrants 
HIV prevention for Tajik migrant workers

\section{Introduction}

Labor migration is a major contributor to fueling the global AIDS epidemic and also the movement of HIV across country borders and populations. ${ }^{1-3}$ Migrants who inject drugs while in a host country are at especially high risk due to behaviors that are exacerbated by social marginalization and lack of access to health care and preventive services. ${ }^{4}$ Tajikistan, a small country in Central Asia with a high unemployment rate and growing drug epidemic, exports more than a million Tajiks annually, many of whom inject drugs, to work outside of their own country. ${ }^{5,6}$ Russia, with one of the world's highest drug-related HIV rates, is a major destination.

Our research among Tajik male migrants who inject drugs in Moscow showed alarmingly high normative and behavioral risk for HIV due to risky drug use, needle sharing, alcohol consumption at behavioral disinhibiting levels, and unsafe sex with casual and paid sex partners. ${ }^{7}$ Yet, little exists in the way of HIV prevention programming for migrants who inject drugs in Russia ${ }^{4}$ or even prevention models for migrants worldwide. ${ }^{8} \mathrm{~A}$ grave need exists for a targeted culturally and contextually congruent HIV preventive intervention for drug users. ${ }^{9}$

This research developed and pilot tested the Migrants' Approached Self-Learning Intervention in HIVIAIDS for Tajiks (MASLIHAT) intervention model for reducing risky drug, alcohol, and sexual behavior among male Tajik migrants who inject drugs while living in Moscow. MASLIHAT was developed as a socio-cultural adaption of the Self-Help in Eliminating Life-Threatening Diseases (SHIELD) model, which is designated by the CDC as a best practice, evidenced-based HIV behavioral intervention for use in the U.S. ${ }^{10}$ Like SHIELD, MASLIHAT is guided by social network theory, ${ }^{11}$ according to which, as one or two influential members of a social network change, others do so as well. A key to promoting safer behavior lies in embedding members within networks as a catalyst to change. We also draw on Yang's Theory of Migration, ${ }^{12}$ which posits that successfully changing risk behavior requires modifying the psycho-social conditions and life circumstance that help to generate it. 
HIV prevention for Tajik migrant workers

By transforming their own HIV norms and behavior, and encouraging others at risk to do so too, migrant peer educators can initiate positive changes at the individual and social network levels in both their host and also their home country when they return.

\section{Methods}

Intervention Development. MASLIHAT is a small-group, interactive intervention that relies on peer networks to reduce drug, alcohol, and sexual risk behaviors among temporary migrant workers who inject drugs. Migrants in the host country who are current or former IDUs are trained as peer educators (PEs) to promote positive HIV risk-reduction norms and behavioral change through role modeling and sharing what they learned during MASLIHAT training sessions with their at-risk network members, especially other PWID. The intervention includes 5 HIV knowledge and skill-building sessions that involve goal setting, role playing, demonstrations, homework, and group discussions. These sessions teach participants techniques for personal risk reduction and the communication and outreach skills needed to encourage others at HIV risk to adopt them as well. As migrants often confront special challenges based on social marginalization and economic disadvantage as a population within the host country, ${ }^{13-20}$ MASLIHAT sessions also address lifestyle, health, and safety issues.

The 5 sessions are: 1) Introduction to MASLIHAT; general risks and safety for Tajik migrant workers; living a healthy lifestyle, resources \& organizations serving Tajik migrants; 2) HIV 101; peer communication skills; 3) HIVISTI risk/prevention thorough hazardous alcohol consumption/unsafe sex; 4) HIV risk/prevention related to drug use; 5) Maintaining a healthier lifestyle; graduation. Homework and case studies in each session help to script peer educator messages.

The steps of intervention development included: 1) solicit input from community leaders, 2) pretest the intervention with a small group of participants and conduct focus groups to collect feedback, 3) conduct supervised practice for facilitators, and 4) develop and pre-test the assessment instrument in preparation for pilot testing. A community advisory board $(C A B)$ reviewed a working draft of the 
HIV prevention for Tajik migrant workers

MASLIHAT manual and provided important insights that were useful in identifying and recruiting effective peer educators, and modifying session content. Eight active or former IDUs recruited through the Tajik Union in Moscow were invited to participate in a pre-test of all 5 MASLIHAT sessions (2 hours each) followed by a one-hour focus group critique. Focus group discussions addressed key topics such as attendees' comfort with the content of the intervention, cultural appropriateness for use with Tajik migrants, perceived feasibility of its homework assignments, usefulness of the session content for reducing HIV risk, and suggested modifications. Finally, five Tajik migrants were invited to assist in developing and pre-testing the questionnaire. In addition to new questions relevant to adapting the MASLIHAT model for a new population, key items were drawn from those successfully used in a prior Moscow/Tajik study and in testing the original SHIELD model in the U.S.

Pilot test and evaluation procedures. Procedures for the pilot test included: 1) recruit PEs and network members, 2) conduct baseline interviews, 3) conduct MASLIHAT sessions with 4 cohorts of PEs, and 4) conduct follow-up interviews at 6 weeks, 3 months, and 6 months following the final intervention session.

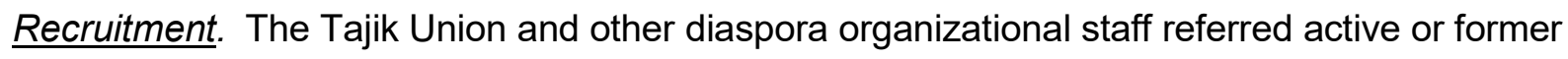
PWID who appeared to meet the study's eligibility criteria for peer educators to PRISMA for screening. Consistent with the SHIELD Mode ${ }^{21}$ and social cognitive theory of peer influence, ${ }^{22,23}$ we asked them to recommend individuals who were respected and influential within local drug-using communities and whose advice would be taken seriously by their peers. To be eligible as a peer educator, prospective participants needed to meet the following criteria: be a male Tajik migrant aged 18 or older, be a current or former PWID, give informed consent, intend to reside in Moscow for the next 6 months to participate in the intervention and follow-up data collection, and be willing to recruit two PWID to participate as IDU network members for interviewing. IDU network members must meet the same criteria but also: 1) have injected drugs at least once in the last 30 days; and 2) be someone whom the 
HIV prevention for Tajik migrant workers

PE sees at least once a week. Peer educators could refer network members after their own enrollment but before beginning the MASLIHAT sessions so that all three were interviewed at baseline before PE training and outreach activities began. Participants received the customary compensation in Moscow of \$20.00 for their time and transportation costs in participating in MASLIIHAT intervention sessions (PEs only) and for being interviewed at baseline, post- intervention, and follow-up (both PEs and network members).

Baseline interviews. The baseline interviews were conducted at the PRISMA office in Moscow.. MASLIHAT. We conducted 4 cycles of the MASLIHAT 5-session trainings sequentially with 7 to 10 PEs per cycle (30 total). The PEs, in turn, were asked to share what they learned with others in their social networks, including the two network members who were enrolled in the study. Because migrant workers are often stopped by police for document check at certain subway stops, group facilitators accompanied PEs to and from those stations to the PRISMA office for the group sessions.

Follow-up. Both PEs and network members were interviewed at 6 weeks, 3 months, and 6 months post-intervention. Interviews often were conducted at a location of the participant's choice close to their home and far from the PRISMA office due to fear of being detained by police. When a participant was too "high" to participate, the interview was rescheduled for another day. The 6-month follow-up interviews that were scheduled to be held at the beginning of July 2018 were delayed until mid-July to avoid having them overlap with the World Soccer Championship that was held in Moscow. This was a high security period that placed migrants at high risk for detention and possible deportation.

Measures. The baseline questionnaire collected information on sociodemographic characteristics, migration characteristics and community involvement, substance use prior to migration and in the past six months in Moscow, sexual risk behavior, IDU network and injection risk behavior, and HIV-related knowledge and attitudes. The measures used in this analyses are described below. 
HIV prevention for Tajik migrant workers

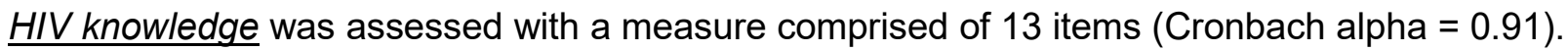
Eight items assessed knowledge of HIV transmission and non-transmission routes with response options being "safe", "unsafe", or "not sure". Five additional true-false items assessed HIV-related knowledge such "You can look at a person and tell if they are infected with HIV," and "There is a cure for HIV." The measure was scored by summing the number of correct responses, with responses of "not sure" counted as incorrect. Participants were also asked to rate their likelihood of being infected with HIV as "not at all likely", "somewhat likely", or "very likely."

Alcohol use measures included frequency of alcohol use in the past month and heavy drinking. Participants were asked "About how many times in the past month have you used alcohol, including beer, wine, or vodka?" Heavy drinking was assessed with the question "How often do you have 6 or more drinks on one occasion," with responses on a 5-point scale from "never" to "daily or nearly daily." No participants endorsed greater than monthly heavy drinking, therefore responses were dichotomized as less than monthly vs. at least monthly.

Sexual risk behavior outcomes included having sex with a sex worker in the past month, and having sex without a condom. Condom use with a regular sexual partner in Moscow and with sex workers was assessed separately on a 4-point scale: "never", "sometimes", "often”, or "always". These items were combined to create a binary measure of any condomless sex.

Injection risk behavior measures included using a shared syringe in the past month, and cleaning syringes with bleach or water. Syringe sharing was assessed with the question, "When was the last time that you used a needle to shoot drugs after someone else used it first?" with options: never, more than 4 weeks ago, in the last 4 weeks, within the last week, yesterday, or today. Responses were dichotomized to create a binary measure of having used a shared syringe within the past month. Participants were asked about syringe cleaning practices with the question "When you have used a needle after someone else, how often did you clean the syringe with [bleach, alcohol, water only, soap and water, or nothing]" with response options on a 6-point scale from "never" to 
HIV prevention for Tajik migrant workers

"always". Alcohol was never used by participants; soap was never used at baseline and rarely used during follow-up. We combined responses to create a measure of frequency of cleaning with bleach or water with three levels: never or rarely, sometimes, or always.

Process measures and MASLIHAT participant feedback. Process measures used after each MASLIHAT session assessed whether or not the session and its content were presented engagingly and as intended. Participants completed a brief written report and checklist of answers to questions asking them to rate the facilitators' delivery of the intervention sessions. They indicated their perceptions of the acceptability and relevance of session topics/activities, likelihood of being able to deliver the information as suggested, and perceptions of whether or not Tajik network peers whom they know would benefit from and use the session information. Discussions of homework during the session included participants reporting on whether or not they had used or shared what they learned the previous week with their peers. Also, each facilitator wrote an overall description of the group session, any problems or challenges encountered in delivering the intervention, and accomplishments of the group (if any).

Analysis. We estimated a mixed effects regression model with random subject and recruiter intercepts to test changes in HIV knowledge from baseline to 6-week follow-up. For dichotomous risk behavior outcomes assessed over the 6-month follow-up period, we estimated population-averaged Poisson regression models with a robust (sandwich) error variance using GEE to obtain risk ratios. ${ }^{24-26}$ We also estimated mixed effects logistic regression models with random subject and recruiter intercepts for comparison of effect sizes, and to compute predicted probabilities. For the count outcome of alcohol use in the past month, we estimated a Poisson mixed effects regression.

In the mixed models, if recruitment group clustering was not significant, the recruiter effect was dropped and a 2-level model was estimated. We included a participant type by time interaction term to assess whether or not the intervention had differential impact on PEs compared to network members. If 
HIV prevention for Tajik migrant workers

the $p$-value for the interaction effect was $>0.05$, the interaction effect was dropped from the model. We also tested the contribution of HIV knowledge to changes in condom use and syringe sharing by including a time by knowledge score interaction in the regressions. Knowledge scores were meancentered at each time point.

\section{Results}

Participation and retention. Thirty Tajik migrants who injected drugs were recruited to participate in the MASLIHAT intervention, and each PE recruited two network members. All PEs and network members completed the baseline interview $(\mathrm{N}=90)$. Nearly all PEs completed the entire sequence of five MASLIHAT sessions; three participants each missed one session, and two participants were removed due to intoxication. Table 1 shows demographic characteristics of PEs and network members at baseline. No PEs were lost to follow-up; three of the 60 network members left Moscow, two were lost at 3 months, and one at six months, resulting in a $95 \%$ follow-up rate at six months.

HIV knowledge and beliefs. The average HIV transmission knowledge score was 7.59 (SE 0.28) at baseline (58\% correct) and increased significantly to 12.43 (SE 0.28) at 6-week follow-up (B=4.84, 95\% Cl 4.15-5.54). In mixed effects regression models, knowledge scores of network members were not significantly different from those of PEs. Both PEs and network members showed increases in perceptions of their own risk for HIV at six weeks that persisted through the six-month follow-up (see Table 2).

Behavioral Outcomes. Model results for behavioral outcomes including high-risk alcohol use, sexual risk behavior, and injection risk behavior are presented in Table 3, and predicted values are shown in Table 4.

Alcohol. Outcomes for alcohol use included number of times used alcohol in the past month, and heavy drinking (6 or more drinks on one occasion). Both measures of alcohol use showed 
HIV prevention for Tajik migrant workers

significant reductions in both 6-week and 3-month follow-up interviews. At the 6-month follow-up, heavy drinking remained low and the number of times used alcohol in the past month continued to decline.

Sexual risk. Outcomes for sexual behavior included having sex with a sex worker in the past month, and having sex without a condom. Both PEs and network members were less likely to report sex with a sex worker on follow-up, with a significant decline at each follow-up time point. Sex without a condom also decreased for both groups at 6 weeks and at 3 months, and the effect was sustained through 6 months. Since only one person reported unprotected sex at the six-month follow-up, additional analyses were restricted to the 6-week and 3-month follow-ups. Paradoxically, greater HIV knowledge was associated with a greater likelihood of condomless sex (OR $=1.92,95 \% \mathrm{Cl} 1.20-3.08)$. The interaction of knowledge score with time was not significant.

Injection risk. Outcomes for injection risk included using a shared syringe in the past month, and cleaning syringes with bleach or water. Use of shared syringes decreased significantly for both groups at 6 weeks and at 3 months, and the effect was sustained through 6 months. At the 3 -month follow-up, only $2 \%(2 / 88)$ of participants reported using a shared syringe within the past 4 weeks. At the 6 -month follow-up none of the participants reported using a shared syringe in the past 4 weeks. Syringe cleaning increased substantially on follow-up in both groups, with $83 \%$ always cleaning their syringes with water at 6 weeks, increasing only slightly to $87 \%$ at 3 months (Table 5). Cleaning with bleach was less prevalent, with $49 \%$ reporting cleaning with bleach often or sometimes at the 3-month and 6-month follow-ups. HIV knowledge had a significant negative effect on syringe sharing (baseline $\mathrm{OR}=0.82$, $95 \% \mathrm{Cl} 0.71-0.95)$, and the interaction with time was not significant.

\section{Qualitative feedback on feasibility and acceptability.}

Peer educator evaluation of facilitator performance and intervention content. Facilitators received high appraisal by PEs because of their non-judgmental, open, friendly, and supportive attitude. PEs reported a high level of satisfaction with the sessions deliver by facilitators and felt that the content 
HIV prevention for Tajik migrant workers

was culturally relevant for Tajik migrants who inject drugs. They reported that they found the

information delivered in the session to be very useful, and that they actively shared the information with their network members. For example, we received the following comments:

"Even my brothers do not talk to me like these guys here, gentle and with understanding, as if they were my own real brothers."

"Usually, people avoid you when they know that you are drug user. Here to the contrary they attract you, invite you and try to help you to be safe. This is what we need."

"It is not a lesson as we used to have at school, boring and uninteresting. It is like a talk in a circle of friends, it is interesting and useful."

"It is more like a game, kind of educational game which is interesting and helpful."

"Some Tajik people say that condom is not culturally proper for us, but I think they would change their mind after they know what HIV is and the number of HIV infected in Tajikistan. I changed my mind now and I think condom is relevant to all cultures."

"Everything that helps people to stay healthy and to stay alive is culturally proper for everybody. These sessions are saving our lives; therefore, they should be part of our culture."

"We didn't know for many years that we could use even water to clean our syringe and needle and to protect ourselves from HIV."

"Some of us knew before that sharing needle is risky, but these sessions really gave us a "push" in order to act and to find new syringes and needles and stop sharing them."

"I think many of Tajik guys could be saved if we had these sessions some years before. They are really helpful and an only way to save our youngsters."

Two criticisms of the MASLIHAT curricula were offered. Discussion of female condoms was seen as culturally inappropriate as Tajik norms place men in charge of contraception. Using a demonstration model to show putting on a condom properly was judged as culturally offensive. Verbal explanation was considered sufficient.

Facilitator evaluations. Session facilitators reported that they started using the information from sessions in their own life. For example:

"As it was said in the sessions, if a leader is not following the recommendations for reducing risk himself, then he won't be able to convince others that it is useful. Therefore, I strictly use every lesson I learned here."

"Our lives depend on each other. If I won't protect myself and if I won't teach my friends how to be safe, then one day we would regret this. That's why I stopped sharing needles and my buddies also followed me." 
HIV prevention for Tajik migrant workers

"It was a little unusual during the first week to clean my needle before injecting, but then everything seemed normal. Now all of us clean our needle though we try not to share needles anymore."

“My girlfriend was happy when I offered myself to use a condom. She first didn't believe it."

\section{Discussion}

The MASLIHAT intervention was well accepted by male Tajik migrant workers in Moscow who inject drugs and the pilot study showed promising effects on reducing HIV risk behavior among both peer educators and network members. HIV knowledge, condom use, and syringe cleaning increased among both participants and their network peers accompanied by a decrease in high-risk alcohol use and syringe sharing. Bleach, however, was used by only about half of those respondents who had shared a syringe in the previous 3 months, and those who did used it inconsistently.

MASLIHAT meets the vital need globally for a successful HIV intervention for male temporary labor migrants who use drugs in their host country. The intervention fits well with the prevention needs of Tajik men who inject drugs living in diaspora. It is delivered by migrants to migrants, and not dependent on support from a host national health care system that denies them access to services. Using current and former PWID to recruit and teach other PWID can reach migrant drug-using populations that are hidden or hard-to-reach. It addresses risk reduction at both the individual and network levels and requires little resource investment to implement. To date, only a few interventions for labor migrants have been developed or tested despite their considerable vulnerability to HIV. Yet, the need for such interventions is pressing. ${ }^{27}$ This research helps to fill that gap. 
Table 1: Demographic characteristics of peer educators and network members enrolled in pilot testing the MASLIHAT model

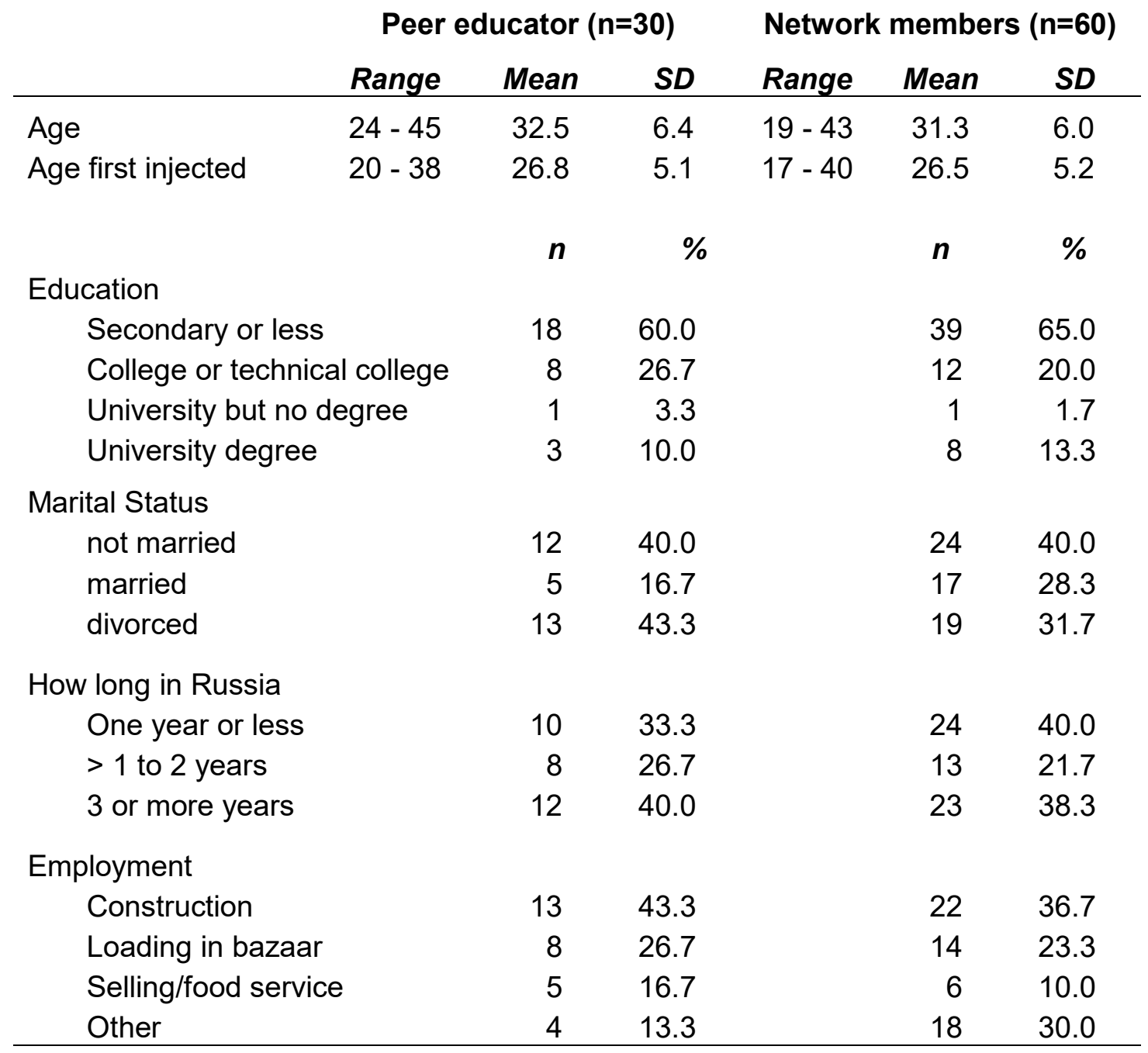


HIV prevention for Tajik migrant workers

Table 2. Beliefs about personal HIV risk among peer educators and network members enrolled in pilot testing the MASLIHAT model $(n=90)$

\begin{tabular}{lrrrrrrrr} 
& \multicolumn{2}{c}{ Baseline } & \multicolumn{2}{c}{$\mathbf{6}$ weeks } & \multicolumn{2}{c}{$\mathbf{3}$ months } & \multicolumn{2}{c}{$\mathbf{6}$ months } \\
& $\mathbf{n}$ & $\mathbf{\%}$ & $\mathbf{n}$ & $\mathbf{\%}$ & $\mathbf{n}$ & $\mathbf{\%}$ & $\mathbf{n}$ & $\mathbf{\%}$ \\
\hline How likely to get HIV & & & & & & & & \\
$\quad$ Not at all & 37 & 41.1 & 5 & 5.6 & 2 & 2.3 & 2 & 2.3 \\
Somewhat & 46 & 51.1 & 62 & 68.9 & 63 & 71.6 & 62 & 71.3 \\
$\quad$ Very & 7 & 7.8 & 23 & 25.6 & 23 & 26.1 & 23 & 26.4
\end{tabular}

How likely at least one person you inject drugs with has HIV

$\begin{array}{lrrrrrrrr}\text { Not at all } & 45 & 50.0 & 1 & 1.1 & 0 & 0.0 & 0 & 0.0 \\ \text { Somewhat } & 39 & 43.3 & 61 & 67.8 & 62 & 70.5 & 61 & 70.1 \\ \text { Very } & 6 & 6.7 & 28 & 31.1 & 26 & 29.5 & 26 & 29.9\end{array}$

How likely you have shared syringes with someone who has HIV

$\begin{array}{lrrrrrrrr}\text { Not at all } & 46 & 51.1 & 26 & 28.9 & 20 & 22.7 & 20 & 23.0 \\ \text { Somewhat } & 37 & 41.1 & 42 & 46.7 & 47 & 53.4 & 46 & 52.9 \\ \text { Very } & 7 & 7.8 & 22 & 24.4 & 21 & 23.9 & 21 & 24.1\end{array}$

How much you worry about HIV

$\begin{array}{lrrrrrrrr}\text { Not at all } & 54 & 60.0 & 1 & 1.1 & 0 & 0.0 & 0 & 0.0 \\ \text { Somewhat } & 36 & 40.0 & 32 & 35.6 & 31 & 35.2 & 31 & 35.6 \\ \text { A lot } & 0 & 0.0 & 57 & 63.3 & 57 & 64.8 & 56 & 64.4\end{array}$


Table 3. Time and participant type effects in follow-up to MASLIHAT intervention: Mixed effects and population-averaged (GEE) regression models $(n=90)$

\begin{tabular}{|c|c|c|c|c|}
\hline & & & Co & rasts $^{c}$ \\
\hline $\begin{array}{l}\text { Past month alcohol use } \\
\text { (\# times) }^{\mathrm{a}}\end{array}$ & IRR & 95\% Conf. Int. & chi2 & p-value \\
\hline 6 weeks & 0.70 & $(0.632-0.784)$ & 41.15 & $<0.001$ \\
\hline 3 months & 0.58 & $(0.493-0.687)$ & 11.39 & 0.0007 \\
\hline 6 months & 0.39 & $(0.297-0.508)$ & 19.4 & $<0.001$ \\
\hline Network member vs. PE & 1.01 & $(0.826-1.225)$ & & \\
\hline Any Heavy drinking ${ }^{b}$ & $\mathbf{R R}$ & 95\% Conf. Int. & & \\
\hline 6 weeks & 0.64 & $(0.422-0.959)$ & 4.67 & 0.0308 \\
\hline 3 months & 0.42 & $(0.247-0.729)$ & 7.27 & 0.007 \\
\hline 6 months & 0.44 & $(0.257-0.742)$ & 1.02 & 0.313 \\
\hline Network member vs. PE & 1.04 & $(0.635-1.692)$ & & \\
\hline Any sex work partner ${ }^{b}$ & & & & \\
\hline 6 weeks & 0.69 & $(0.541-0.871)$ & 9.62 & 0.0019 \\
\hline 3 months & 0.40 & $(0.275-0.572)$ & 13.48 & 0.0002 \\
\hline 6 months & 0.20 & $(0.111-0.355)$ & 9.04 & 0.0026 \\
\hline Network member vs. PE & 1.09 & $(0.737-1.611)$ & & \\
\hline Sex without condom ${ }^{b}$ & & & & \\
\hline 6 weeks & 0.40 & $(0.251-0.637)$ & 14.94 & 0.0001 \\
\hline 3 months & 0.10 & $(0.035-0.299)$ & 7.39 & 0.0066 \\
\hline 6 months & 0.03 & $(0.005-0.231)$ & 1.84 & 0.1751 \\
\hline Network member vs. PE & 0.85 & $(0.447-1.612)$ & & \\
\hline Injected with used syringe $e^{b, d}$ & & & & \\
\hline 6 weeks & 0.47 & $(0.313-0.700)$ & 13.7 & 0.0002 \\
\hline 3 months & 0.04 & $(0.011-0.181)$ & 12.26 & 0.0005 \\
\hline Network member vs. PE & 1.21 & $(0.789-1.849)$ & & \\
\hline
\end{tabular}

${ }^{a}$ mixed effects Poisson regression

${ }^{b}$ GEE Poisson regression with robust variance estimator

${ }^{\mathrm{c}}$ reverse adjacent contrasts for time effects

${ }^{d} 6$-month data omitted: $0 \%$ injected with used syringe at 6 months

PE: peer educator 
Table 4. Predicted values of outcomes from mixed effects regression models $(n=90)$

\begin{tabular}{|c|c|c|c|c|c|c|c|c|}
\hline & \multicolumn{4}{|c|}{ Peer Educator } & \multicolumn{4}{|c|}{ Network member } \\
\hline & BL & 6 wks & 3 mos & mos & BL & 6 wks & 3 mos & $6 \mathrm{mos}$ \\
\hline \multicolumn{9}{|l|}{ Alcohol use } \\
\hline Past month alcohol use (\# times) ${ }^{a}$ & 4.99 & 3.51 & 2.90 & 1.94 & 5.02 & 3.53 & 2.92 & 1.95 \\
\hline Heavy drinking (6 or more drinks) ${ }^{b}$ & 0.35 & 0.22 & 0.14 & 0.15 & 0.38 & 0.24 & 0.16 & 0.16 \\
\hline \multicolumn{9}{|l|}{ Sexual risk } \\
\hline Had sex with sex worker ${ }^{c}$ & 0.51 & 0.34 & 0.18 & 0.08 & 0.60 & 0.43 & 0.25 & 0.12 \\
\hline Had sex without condom ${ }^{c}$ & 0.41 & 0.18 & 0.05 & 0.01 & 0.30 & 0.11 & 0.02 & 0.01 \\
\hline $\begin{array}{l}\text { Injection risk } \\
\text { Injected with used syringe past } 4 \\
\text { weeks }^{\mathrm{c}}\end{array}$ & 0.47 & 0.21 & 0.02 & - & 0.55 & 0.26 & 0.03 & - \\
\hline
\end{tabular}


HIV prevention for Tajik migrant workers

Table 5. Prevalence of syringe cleaning among participants injecting with a used syringe

\begin{tabular}{cllllllll} 
& \multicolumn{2}{c}{ Baseline } & \multicolumn{2}{c}{$\mathbf{6}$ weeks } & \multicolumn{2}{c}{$\mathbf{3}$ months } & \multicolumn{2}{c}{$\mathbf{6}$ months } \\
& $\boldsymbol{n}$ & $\mathbf{\%}$ & $\boldsymbol{n}$ & $\mathbf{\%}$ & $\boldsymbol{n}$ & $\mathbf{\%}$ & $\boldsymbol{n}$ & $\mathbf{\%}$ \\
\hline $\begin{array}{c}\text { Cleaned syringe } \\
\text { (by any means) }\end{array}$ & & & & & & & & \\
$\quad$ Never/rarely & 26 & 35.1 & 0 & 0.0 & 0 & 0.0 & 0 & 0.0 \\
$\quad$ Sometimes & 48 & 64.9 & 12 & 16.7 & 9 & 12.9 & 9 & 13.0 \\
$\quad$ Always & 0 & 0.0 & 60 & 83.3 & 61 & 87.1 & 60 & 87.0 \\
\hline
\end{tabular}


HIV prevention for Tajik migrant workers

\section{Acknowledgements}

Research reported in this publication was supported by the National Institute on Drug Abuse of the National Institutes of Health (USA) under Award Number R21DA039068. The content is solely the responsibility of the authors and does not necessarily represent the official views of the National Institutes of Health. We thank the Tajik Diaspora Union for its assistance and also the study's participants and members of the MASLIHAT staff for making this research possible. 
HIV prevention for Tajik migrant workers

\section{References}

1. UNAIDS, International Organization for Migration. Migration and AIDS. International Migration. 1998;36(4):445-468.

2. Del Amo J, Bröring G, Hamers FF, Infuso A, Fenton K. Monitoring HIVIAIDS in Europe's migrant communities and ethnic minorities. AIDS. 2004;18(14):1867-1873.

3. El-Bassel N, Gilbert L, Shaw SA, et al. The Silk Road Health Project: How mobility and migration status influence HIV risks among male migrant workers in Central Asia. PLOS ONE. 2016;11(3):e0151278.

4. Weine SM, Kashuba AB. Labor migration and HIV risk: A systematic review of the literature. AIDS Behav. 2012;16(6):1605-1621.

5. Olimova S, Bosc I. Labor Migration from Tajikistan. Geneva: International Organization for Migration; July 2003.

6. World Health Organization (WHO). Epidemiological Factsheet: Tajikistan: UNAIDS; 2010.

7. Bakhromov M, Levy JA. Double jeopardy through social marginalization: HIV risk among Tajik male labor migrants in Moscow. Drug Alcohol Depend. 2013;132, Supplement 1:S53-S55.

8. Deren S, Shedlin M, Decena CU, Mino M. Research challenges to the study of HIVIAIDS among migrant and immigrant Hispanic populations in the United States. J. Urban Health. 2005;82(3):iii13-iii25.

9. Needle R, Zhao L. HIV Prevention Among Injection Drug Users: Strengthening U.S. Support for Core Interventions. Washington, DC: Center for Strategic \& International Studies.

10. HIVIAIDS Prevention Research Synthesis Project. Compendium of Evidence-Based Interventions and Best Practices for HIV Prevention. Self-Help in Eliminating Life-Threatening Diseases (SHIELD): Centers for Disease Control and Prevention; https://www.cdc.gov/hiv/research/interventionresearch/compendium/index.html. January 7 , 2020. Accessed Jan 29, 2021. 
HIV prevention for Tajik migrant workers

11. Hall A, Wellman B. Social networks and social support. In: Cohen S, Syme L, eds. Social Support and Health. New York: Academic Press; 1985:23-41.

12. Yang X. Temporary migration and HIV risk behaviors in China. Environment and Planning. 2006;38:1527-1543.

13. Snipes SA, Cooper SP, Shipp EM. "The only thing I wish I could change is that they treat us like people and not like animals": Injury and discrimination among Latino farmworkers. J. Agromedicine. 2017;22(1):36-46.

14. Kosny A, Santos I, Reid A. Employment in a "land of opportunity?" Immigrants' experiences of racism and discrimination in the Australian workplace. Int. Migration \& Integration. 2017;18(2):483-497.

15. Md MR, Subramaniam T, Islam MR. Economic and social well-being of Asian labour migrants: A literature review. Soc. Indic. Res. 2019;141(3):1245-1264.

16. Heywood AE, Lopez-Velez R. Reducing infectious disease inequities among migrants. J. Trave/ Med. 2019;26(2).

17. Green O, Ayalon L. Violations of workers' rights and exposure to work-related abuse of live-in migrant and live-out local home care workers - a preliminary study: Implications for health policy and practice. Isr. J. Health Policy Res. 2018;7(1):32.

18. Frost DM. Hostile and harmful: Structural stigma and minority stress explain increased anxiety among migrants living in the United Kingdom after the Brexit referendum. J Consult Clin Psychol. 2020;88(1):75-81.

19. Bagong S, Rahma S, Sutinah, Medhy H. Bargaining the future: A descriptive study of the lives of the Indonesian illegal migrant workers. Int. Migration \& Integration. 2020;21(1):185-204.

20. Cailhol J, Khan N. Chronic hepatitis and HIV risks amongst Pakistani migrant men in a French suburb and insights into health promotion interventions: The ANRS Musafir qualitative study. BMC Public Health. 2020;20(1):1393. 
HIV prevention for Tajik migrant workers

21. Latkin CA, Sherman S, Knowlton A. HIV prevention among drug users: Outcome of a networkoriented peer outreach intervention. Health Psychology. 2003;22(4):332-339.

22. Valente TW. Network models of the diffusion of innovations. Cresskill, NJ: Hampton Press; 1995.

23. Valente TW, Davis RL. Accelerating the diffusion of innovations using opinion leaders. The Annals of the American Academy of Political and Social Science. 1999;566(1):55-67.

24. Salter AB, Ryan P, Yelland LN. Performance of the modified Poisson regression approach for estimating relative risks from clustered prospective data. Am. J. Epidemiol. 2011;174(8):984992.

25. Zou G. A modified Poisson regression approach to prospective studies with binary data. Am. J. Epidemiol. 2004;159(7):702-706.

26. Zou G, Donner A. Extension of the modified Poisson regression model to prospective studies with correlated binary data. Stat. Methods Med. Res. 2013;22(6):661-670.

27. Godinho J, Renton A, Vinogradov V, Novotny T, Rivers M-J. Reversing the Tide: Priorities for HIVIAIDS Prevention in Central Asia. Washington, D.C.: World Bank. 0821362305. 